\title{
Directing the Metabolism of Drugs Away from CYP450: The Use of Oxetane Rings
}

\author{
Robert B. Raffa ${ }^{1,2,3,4^{*}}$, Joseph V. Pergolizzi Jr. ${ }^{1,2,5}$ \\ ${ }^{1}$ Neumentum Inc., Palo Alto, CA, USA \\ ${ }^{2}$ Enalare LLC, Naples, FL, USA \\ ${ }^{3}$ College of Pharmacy, University of Arizona, Tucson, AZ, USA \\ ${ }^{4}$ Temple University School of Pharmacy, Philadelphia, PA, USA \\ ${ }^{5}$ NEMA Research Inc., Naples, FL, USA \\ Email: *robert.raffa@temple.edu
}

How to cite this paper: Raffa, R.B. and Pergolizzi Jr., J.V. (2019) Directing the Metabolism of Drugs Away from CYP450: The Use of Oxetane Rings. Pharmacology \& Pharmacy, 10, 465-473.

https://doi.org/10.4236/pp.2019.1011038

Received: October 2, 2019

Accepted: November 2, 2019

Published: November 5, 2019

Copyright $\odot 2019$ by author(s) and Scientific Research Publishing Inc. This work is licensed under the Creative Commons Attribution International License (CC BY 4.0).

http://creativecommons.org/licenses/by/4.0/

\begin{abstract}
Treatment of health problems that accompany aging often includes pharmacotherapy. It is thus common for older adults-and, increasingly, younger adults-to be on multiple medications, either prescription or over-the-counter (OTC). With the consumption of multiple medications, drug-drug interactions (DDIs) are a concern. The site of drug-drug interactions is often at the level of drug metabolism. If a drug inhibits (or enhances) the metabolism of another, the blood level (therapeutic effect) can be decreased below the required level, or adverse effects can increase. Because most currently used drugs are metabolized via cytochrome $\mathrm{P} 450$-catalyzed pathways, drug discovers seek drugs that are metabolized by alternate pathways. Medicinal chemists have come upon a strategy-the incorporation of oxetane rings in the drug structure-that increases the likelihood that a drug will not be metabolized via CYP450. The same modification gives other desirable physical properties to the molecule. Although there are no guarantees that there will be fewer DDIs or an absence of other unexpected problems, the strategy could pave the way for new drugs that are safer and easier to use with concomitant medications.
\end{abstract}

\section{Keywords}

Drug Metabolism, CYP450, Drug-Drug Interaction, Oxetane, Analgesic, Drug Discovery

\section{Introduction}

In the past century, populations in many parts of the world are aging [1]. And a significant rise in life expectancy in almost all regions of the world has contri- 
buted to an increasingly older population. Since the aging process predisposes a person to increased vulnerability and susceptibility to external threats and internal physiological decline in organ function and defensive processes against disease, concurrent with the increasing population is an increase in the needs for healthcare and related services [2] [3] (Figure 1).

The physiological changes that occur with aging affect the functioning of the heart and blood vessels, gastrointestinal tract, liver, kidneys, central nervous system, and others [4] [5] [6] [7]. With the advances in basic research and translation to drug discovery, a large fraction of healthcare includes pharmacotherapy. Therefore, medication use increases substantially with aging in conjunction with the healthcare needs and, because there is often more than one health problem, polypharmacy is commonly the result [2] [3] [8] [9] [10]. While not inherently a contraindication, polypharmacy can inadvertently lead to serious adverse consequences [11] [12] [13]. The occurrence of such an event is termed a "drug-drug interaction" (DDI). One of the major physiological mechanisms leading to a DDI is an interaction at the level of drug metabolism. The CYP450 system is more affected by the aging process than are other drug metabolizing systems. Therefore, a strategy that could limit the occurrence of a DDI at the level of CYP450 drug metabolism could have a significant benefit.

\section{Drug Metabolism via CYP450}

The CYP450 monooxygenase system is a family of hemeprotein isozymes that catalyze the biotransformation (metabolism) of many current drugs (Figure 2)

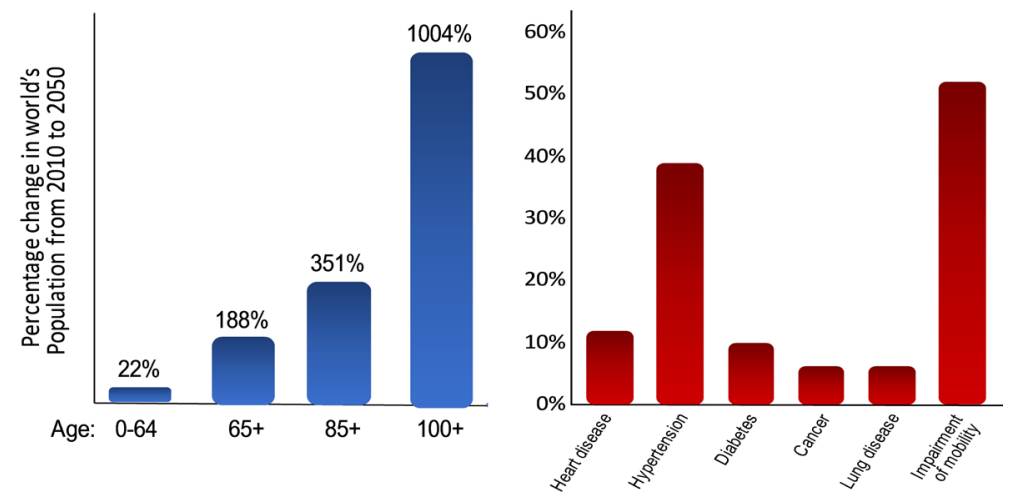

Figure 1. (Left) Increase in world population and (right) prevalence of chronic health problems. Source: United Nations, World Population Prospects: Available at: http://esa.un.org/unpd/wpp.

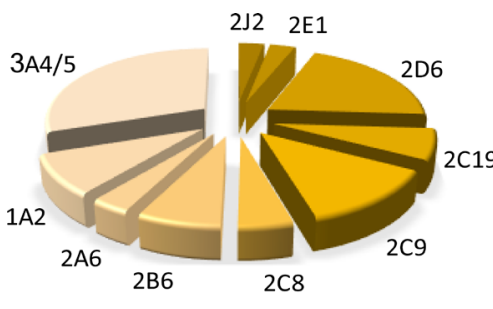

$\begin{array}{lclr}\text { CYP2J2 } & 3 \% & \text { CYP2C8 } & 4.7 \% \\ \text { CYP2E1 } & 3 \% & \text { CYP2B6 } & 7.2 \% \\ \text { CYP2D6 } & 20 \% & \text { CYP2A6 } & 3.4 \% \\ \text { CYP2C19 } & 6.8 \% & \text { CYP1A2 } & 8.9 \% \\ \text { CYP2C9 } & 12.8 \% & \text { CYP3A4/5 } & 30.2 \%\end{array}$

Figure 2. Approximate estimate of the percentage of current drugs that are metabolized via pathways of the CYP isozymes. Based on [15] with permission. 
[14] [15] [16]. The liver is the major site of drug metabolism in humans, functioning both to detoxify (alter the chemical structure) and to facilitate excretion of foreign chemicals (xenobiotics) such as drugs by enzymatically converting lipophilic (lipid-soluble) compounds to less lipophilic (hydrophilic, water-soluble) compounds, which are more favorably excreted through the kidneys. Drug metabolism is achieved through phase I type reactions (chemical reactions such as oxidation, reduction, and hydrolysis), phase II reactions (mostly conjugations), or both (the most frequent situation for most drugs) [17]. Oxidation is the most common of the phase I reactions, and these are catalyzed by members of the CYP450 system. CYP450 was discovered in 1954 as a novel protein in hepatocytes during research on steroid hormone metabolism [18]. It's function and significance as a catalyst in steroid hormone synthesis and drug metabolism was determined almost a decade later (1963), and it was confirmed to be a key enzyme involved in drug and steroid hydroxylation reactions [19].

\section{Oxetanes: The Basics}

Oxetane is a four-member ring organic compound consisting of three carbon atoms and one oxygen atom with formula $\mathrm{C}_{3} \mathrm{H}_{6} \mathrm{O}$ and molecular weight 58.08 Dalton (Figure 3). A drug (or any organic compound) that contains this particular heterocycle is called an "oxetane". The reason that the oxetane ring is of interest to drug discovery as a strategy to reduce DDIs is that compared to a molecule without the ring, the incorporation of an oxetane ring can impart significant differences in the structural and physiochemical properties of molecules, and thus the drug-favoring characteristics of a compound, for example its water or lipid solubility, $\mathrm{p} K_{\mathrm{a}}$, receptor or enzyme conformational preference, and of particular relevance to the present topic-metabolic stability [20] [21].

The oxetane ring can thus be thought of as a functional group, and it can be used as a substitute or as preferred surrogate for other functionalities that are commonly used in drug discovery (Figure 4). Some uses have included [22]

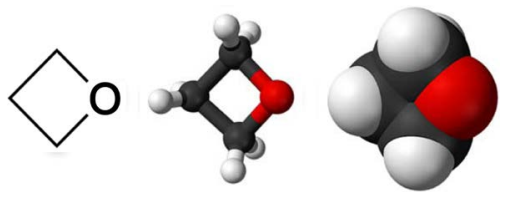

Figure 3. Representations of Oxetane (1,3-Propylene oxide, 1,3-Epoxypropane, Oxacyclobutane, Trimethylene oxide. Source: Wikimepedia and Wikimedia Commons.
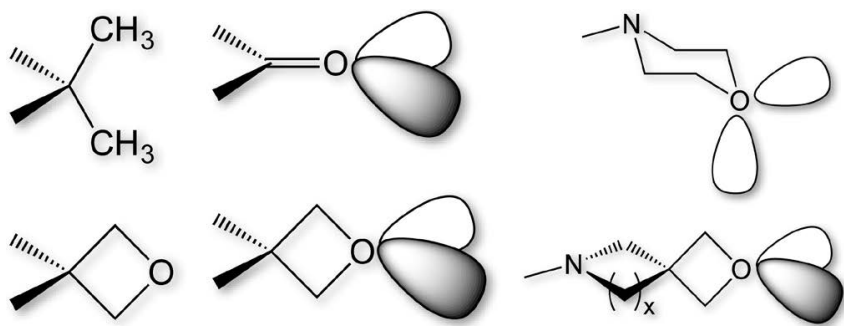

Figure 4. Oxetanes as surrogates for commonly encountered functional groups [22]. 
introduction of steric bulk to fill receptor pockets (for better complementary fit to increase intrinsic activity or block active sites, shield nearby functional groups from chemical or metabolic susceptibility without introducing an undesired increase in lipophilicity [23]-[29]. They have successfully been used to improve the physiochemical properties and provide more favorable pharmacokinetic profiles in several drug discovery programs [30]-[37]. The magnitude of the changes depends on the structural context of course. As an example, substitution with an oxetane can increase the aqueous solubility by only about 4 -fold, or more than an astounding 4000-fold [22]. Substitution usually increases the metabolic stability.

\section{Oxetanes: Designing Away from DDIs}

Toselli et al. have recently reported on the use of oxetane rings as design elements to alter the metabolic pathways of drugs [30]. They "map" the enzymes that contribute to a drug's metabolism to determine exaggerated dependence on one specific pathway (specifically a specific CYP450 pathway), since this increases the risk of DDIs with co-administered drugs. They previously reported that oxetane rings can be hydrolyzed (opened to yield diols) by the human microsomal enzyme epoxide hydrolase (mEH) (EC 3.2.2.9) [38]. This was quite surprising, since it represents an unusual non-oxidative metabolic route, and it was the first example of a non-epoxide substrate for this phase I type drug-metabolizing enzyme [39] [40]. Findings of additional examples of oxetane substrates of $\mathrm{mEH}$ prompted renaming of the enzyme to "microsomal oxirane/oxetane hydrolase" [41].

A critical finding was that the rate of hydrolysis of an oxetane by $\mathrm{mEH}$ is affected by structural elements in the vicinity of the oxetane [41]. This offers the potential that the rate of metabolism could be built-in or fine-tuned by using oxetane-containing building blocks as part of the drug design discovery process as tools to shuttle metabolism through non-CYP450 pathways, thus decreasing the likelihood of a DDI with co-administered other drugs (Figure 5). Indeed,
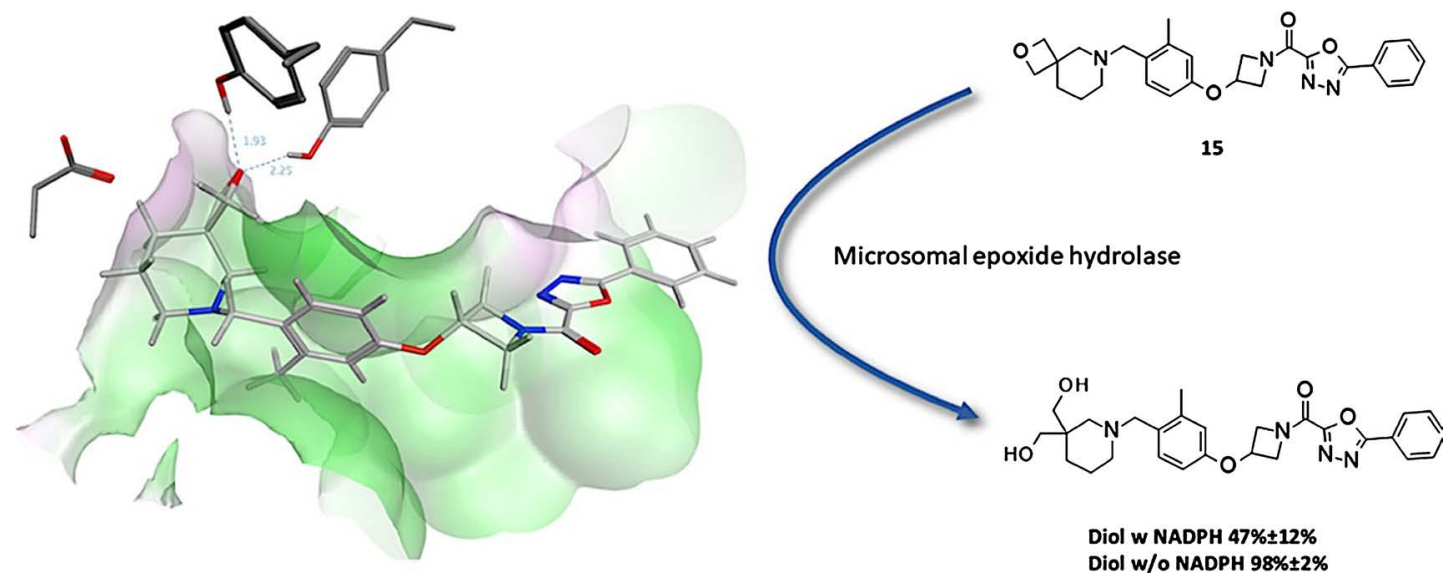

Figure 5. A representative example of a molecule containing an oxetane ring metabolized to a diol in a reaction catalyzed by $\mathrm{mEH}$ (microsomal epoxide hydrolase). Note the opening of the oxetane ring. Source: Ref [30], with permission. 


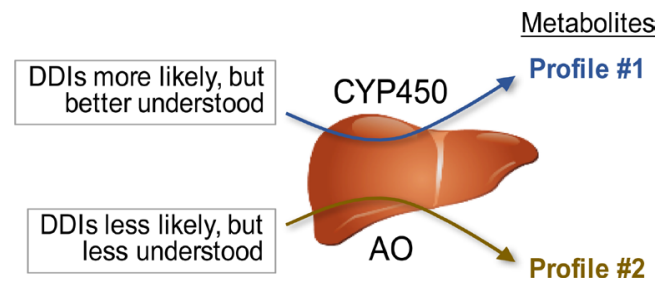

Figure 6. Shuttling of drug metabolism away from CYP450 and towards another enzymatic pathway such as AO (aldehyde oxidase) could be quite beneficial, is not devoid of potential problems.

Toselli et al. demonstrated for a set of structurally diverse oxetanes that oxetanes can be used as design elements for directing drug metabolism toward $\mathrm{mEH}$, and thus away from CYP450 pathways [30].

Toselli et al. expressed a note of caution that the shuttling of drug metabolism down the $\mathrm{mEH}$ pathway 1) did not guarantee avoidance of a DDI, and 2) did not introduce its own set of potential problems [30]. Some problems might be anticipated, such as undesirable effects on pharmacokinetics [42] [43] [44] [45], but other problems might arise simply due to the less mature understanding of this metabolic pathway compared to those of the very well-known CYP450's (Figure 6).

\section{Conclusion}

The fact that the majority of currently prescribed drugs, and several OTC products, are metabolized through the same pathways involving CYP450 raises the concern of potential drug-drug interactions leading to adverse effects that would be avoided if the drugs were metabolized by non-overlapping mechanism. Oxetanes offer a strategy to design-in this capability early in drug discovery. Although not a guarantee, they are one example of a broader attempt to decrease DDIs early in the drug discovery process.

\section{Conflicts of Interest}

The authors declare no conflicts of interest regarding the publication of this paper.

\section{References}

[1] Annonymous (2017) United Nations World Population Ageing-Highlights. https://www.un.org/en/development/desa/population/publications/pdf/ageing/WP A2017_Highlights.pdf

[2] Bergman, H., et al. (2013) Understanding and Meeting the Needs of the Older Population: A Global Challenge. Canadian Geriatrics Journal, 16, 61-65.

https://cgjonline.ca/index.php/cgj/article/view/60 https://doi.org/10.5770/cgj.16.60

[3] Chang, A.Y., Skirbekk, V.F., Tyrovolas, S., Kassebaum, N.J. and Dieleman, J.L. (2019) Measuring Population Ageing: An Analysis of the Global Burden of Disease Study 2017. The Lancet Public Health, 4, e159-e167. https://www.thelancet.com/journals/lanpub/article/PIIS2468-2667(19)30019-2/fullt $\underline{\text { ext }}$ 
https://doi.org/10.1016/S2468-2667(19)30019-2

[4] Boss, G.R. and Seegmiller, J.E. (1981) Age-Related Physiological Changes and Their Clinical Significance. Western Journal of Medicine, 135, 434-440.

https://www.ncbi.nlm.nih.gov/pmc/articles/PMC1273316/pdf/westjmed00220-0011. pdf

[5] McLean, A.J. and Le Couteur, D.G. (2004) Aging Biology and Geriatric Clinical Pharmacology. Pharmacological Reviews, 56, 163-184.

http://pharmrev.aspetjournals.org/content/56/2/163.long https://doi.org/10.1124/pr.56.2.4

[6] Schmucker, D.L. (1985) Aging and Drug Disposition: An Update. Pharmacological Reviews, 37, 133-148. http://pharmrev.aspetjournals.org/content/37/2/133.long https://doi.org/10.1080/03085698508592599

[7] Woodhouse, K. (1992) Drugs and the Liver. Part III: Ageing of the Liver and the Metabolism of Drugs. Biopharmaceutics \& Drug Disposition, 13, 311-320. https://www.ncbi.nlm.nih.gov/pubmed/1498264 https://doi.org/10.1002/bdd.2510130502

[8] Linjakumpu, T., et al. (2002) Use of Medications and Polypharmacy Are Increasing among the Elderly. Journal of Clinical Epidemiology, 55, 809-817.

https://www.jclinepi.com/article/S0895-4356(02)00411-0/fulltext https://doi.org/10.1016/S0895-4356(02)00411-0

[9] Quinn, K.J. and Shah, N.H. (2017) A Dataset Quantifying Polypharmacy in the United States. Scientific Data, 4, Article No. 170167.

https://www.nature.com/articles/sdata2017167 https://doi.org/10.1038/sdata.2017.167

[10] Morin, L., Johnell, K., Laroche, M.L., Fastbom, J. and Wastesson, J.W. (2018) The Epidemiology of Polypharmacy in Older Adults: Register-Based Prospective Cohort Study. Clinical Epidemiology, 10, 289-298.

https://www.dovepress.com/the-epidemiology-of-polypharmacy-in-older-adults-re gister-based-prospe-peer-reviewed-article-CLEP https://doi.org/10.2147/CLEP.S153458

[11] Dagli, R.J. and Sharma, A. (2014) Polypharmacy: A Global Risk Factor for Elderly People. Journal of International Oral Health, 6, 1-2. https://www.ncbi.nlm.nih.gov/pmc/articles/PMC4295469/pdf/JIOH-6-i.pdf

[12] Maher, R.L., Hanlon, J. and Hajjar, E.R. (2014) Clinical Consequences of Polypharmacy in Elderly. Expert Opinion on Drug Safety, 13, 57-65. https://www.tandfonline.com/doi/abs/10.1517/14740338.2013.827660?journalCode =ieds 20 https://doi.org/10.1517/14740338.2013.827660

[13] Khandeparkar, A. and Rataboli, P.V. (2017) A Study of Harmful Drug-Drug Interactions Due to Polypharmacy in Hospitalized Patients in Goa Medical College. Perspectives in Clinical Research, 8, 180-186. http://www.picronline.org/temp/PerspectClinRes84180-4080127_112001.pdf https://doi.org/10.4103/picr.PICR_132_16

[14] Ogu, C.C. and Maxa, J.L. (2000) Drug Interactions Due to Cytochrome P450. Proceedings (Baylor University. Medical Center), 13, 421-423.

https://www.tandfonline.com/doi/pdf/10.1080/08998280.2000.11927719?needAcces $\underline{s=\text { true }}$ https://doi.org/10.1080/08998280.2000.11927719

[15] Zanger, U.M. and Schwab, M. (2013) Cytochrome P450 Enzymes in Drug Metabol- 
ism: Regulation of Gene Expression, Enzyme Activities, and Impact of Genetic Variation. Pharmacology \& Therapeutics, 138, 103-141.

https://www.sciencedirect.com/science/article/pii/S0163725813000065?via\%3Dihub https://doi.org/10.1016/j.pharmthera.2012.12.007

[16] Estabrook, R.W. (2003) A Passion for P450s (Rememberances of the Early History of Research on Cytochrome P450). Drug Metabolism \& Disposition, 31, 1461-1473. http://dmd.aspetjournals.org/content/31/12/1461 https://doi.org/10.1124/dmd.31.12.1461

[17] McDonnell, A.M. and Dang, C.H. (2013) Basic Review of the Cytochrome p450 System. Journal of the Advanced Practitioner in Oncology, 4, 263-268.

https://www.ncbi.nlm.nih.gov/pmc/articles/PMC4093435 https://doi.org/10.6004/jadpro.2013.4.4.7

[18] Klingenberg, M. (1958) Pigments of Rat Liver Microsomes. Archives of Biochemistry and Biophysics, 75, 376-386.

https://www.sciencedirect.com/science/article/abs/pii/0003986158904363?via\%3Dih $\underline{\mathrm{ub}}$ https://doi.org/10.1016/0003-9861(58)90436-3

[19] Cooper, D.Y., Levin, S., Narasimhulu, S. and Rosenthal, O. (1965) Photochemical Action Spectrum of the Terminal Oxidase of Mixed Function Oxidase Systems. Science, 147, 400-402. https://science.sciencemag.org/content/147/3656/400.long https://doi.org/10.1126/science.147.3656.400

[20] Bull, J.A., Croft, R.A., Davis, O.A., Doran, R. and Morgan, K.F. (2016) Oxetanes: Recent Advances in Synthesis, Reactivity, and Medicinal Chemistry. Chemical Reviews, 116, 12150-12233. https://doi.org/10.1021/acs.chemrev.6b00274 https://pubs.acs.org/doi/pdf/10.1021/acs.chemrev.6b00274?rand=pf5dnqxs

[21] Carreira, E.M. and Fessard, T.C. (2014) Four-Membered Ring-Containing Spirocycles: Synthetic Strategies and Opportunities. Chemical Reviews, 114, 8257-8322. https://pubs.acs.org/doi/10.1021/cr500127b https://doi.org/10.1021/cr500127b

[22] Wuitschik, G., et al. (2010) Oxetanes in Drug Discovery: Structural and Synthetic Insights. Journal of Medicinal Chemistry, 53, 3227-3246.

https://pubs.acs.org/doi/abs/10.1021/jm9018788 https://doi.org/10.1021/jm9018788

[23] Magnin, D.R., et al. (2004) Synthesis of Novel Potent Dipeptidyl Peptidase IV Inhibitors with Enhanced Chemical Stability: Interplay between the N-Terminal Amino Acid Alkyl Side Chain and the Cyclopropyl Group of Alpha-Aminoacyl-l-cis-4,5Methanoprolinenitrile-Based Inhibitors. Journal of Medicinal Chemistry, 47, 25872598. https://pubs.acs.org/doi/10.1021/jm049924d https://doi.org/10.1021/jm049924d

[24] von Rauch, M., Schlenk, M. and Gust, R. (2004) Effects of C2-alkylation, N-alkylation, and $\mathrm{N}, \mathrm{N}^{\prime}$-dialkylation on the Stability and Estrogen Receptor Interaction of (4R,5S)/(4S,5R)-4,5-bis(4-hydroxyphenyl)-2-imidazolines. Journal of Medicinal Chemistry, 47, 915-927. https://pubs.acs.org/doi/10.1021/jm0309809 https://doi.org/10.1021/jm0309809

[25] Manoury, P.M., Binet, J.L., Rousseau, J., Lefevre-Borg, F. and Cavero, I.G. (1987) Synthesis of a Series of Compounds Related to Betaxolol, a New Beta 1-Adrenoceptor Antagonist with a Pharmacological and Pharmacokinetic Profile Optimized for the Treatment of Chronic Cardiovascular Diseases. Journal of Medicinal Chemistry, 30, 1003-1011. https://www.ncbi.nlm.nih.gov/pubmed/2884312 https://doi.org/10.1021/jm00389a008 
[26] Borthwick, A.D., et al. (2003) Design and Synthesis of Pyrrolidine-5,5'-trans-lactams (5-oxo-hexahydropyrrolo[3,2-b]pyrroles) as Novel Mechanism-Based Inhibitors of Human Cytomegalovirus Protease. 4. Antiviral Activity and Plasma Stability. Journal of Medicinal Chemistry, 46, 4428-4449.

https://pubs.acs.org/doi/abs/10.1021/jm030810w https://doi.org/10.1021/jm030810w

[27] Madsen, P., et al. (2002) Optimization of Alkylidene Hydrazide Based Human Glucagon Receptor Antagonists. Discovery of the Highly Potent and Orally Available 3-Cyano-4-Hydroxybenzoic Acid [1-(2,3,5,6-tetramethylbenzyl)-1H-indol-4-ylmethylene]hydrazide. Journal of Medicinal Chemistry, 45, 5755-5775.

https://pubs.acs.org/doi/10.1021/jm0208572

https://doi.org/10.1021/jm0208572

[28] Duffy, J.L., et al. (2003) HIV Protease Inhibitors with Picomolar Potency against PI-Resistant HIV-1 by Extension of the P3 Substituent. Bioorganic \& Medicinal Chemistry Letters, 13, 2569-2572. https://doi.org/10.1016/S0960-894X(03)00475-X https://www.sciencedirect.com/science/article/pii/S0960894X0300475X?via\%3Dihub

[29] Ahmad, S., et al. (2001) Arylcyclopropanecarboxyl Guanidines as Novel, Potent, and Selective Inhibitors of the Sodium Hydrogen Exchanger Isoform-1. Journal of Medicinal Chemistry, 44, 3302-3310. https://pubs.acs.org/doi/10.1021/jm010100v https://doi.org/10.1021/jm010100v

[30] Toselli, F., et al. (2019) Hip to Be Square: Oxetanes as Design Elements to Alter Metabolic Pathways. Journal of Medicinal Chemistry, 62, 7383-7399.

https://pubs.acs.org/doi/10.1021/acs.jmedchem.9b00030 https://doi.org/10.1021/acs.jmedchem.9b00030

[31] Stepan, A.F., et al. (2011) Metabolism-Directed Design of Oxetane-Containing Arylsulfonamide Derivatives as Gamma-Secretase Inhibitors. Journal of Medicinal Chemistry, 54, 7772-7783. https://pubs.acs.org/doi/10.1021/jm200893p https://doi.org/10.1021/jm200893p

[32] Lu, H., et al. (2018) Discovery of Novel 1-Cyclopentenyl-3-Phenylureas as Selective, Brain Penetrant, and Orally Bioavailable CXCR2 Antagonists. Journal of Medicinal Chemistry, 61, 2518-2532. https://doi.org/10.1021/acs.jmedchem.7b01854 https://pubs.acs.org/doi/abs/10.1021/acs.jmedchem.7b01854

[33] Crawford, J.J., et al. (2018) Discovery of GDC-0853: A Potent, Selective, and Noncovalent Bruton's Tyrosine Kinase Inhibitor in Early Clinical Development. Journal of Medicinal Chemistry, 61, 2227-2245.

https://doi.org/10.1021/acs.jmedchem.7b01712 https://pubs.acs.org/doi/10.1021/acs.jmedchem.7b01712

[34] Ouvry, G., et al. (2018) Discovery and Characterization of CD12681, a Potent RORgamma Inverse Agonist, Preclinical Candidate for the Topical Treatment of Psoriasis. ChemMedChem, 13, 321-337. https://doi.org/10.1002/cmdc.201700758 https://onlinelibrary.wiley.com/doi/abs/10.1002/cmdc.201700758

[35] Cheong, J.E., et al. (2018) Synthesis and Anticancer Activity of Novel Water Soluble Benzimidazole Carbamates. European Journal of Medicinal Chemistry, 144, 372-385. https://doi.org/10.1016/j.ejmech.2017.11.037 https://www.sciencedirect.com/science/article/pii/S0223523417309406?via\%3Dihub

[36] Geary, G.C., et al. (2018) Densely Functionalised Spirocyclic Oxetane-Piperidine Scaffolds for Drug Discovery. Bioorganic \& Medicinal Chemistry, 26, 791-797. https://pubs.acs.org/doi/full/10.1021/jm9018788?src=recsys https://doi.org/10.1016/j.bmc.2017.12.012

[37] Bezencon, O., et al. (2017) Discovery of a Potent, Selective T-Type Calcium Channel 
Blocker as a Drug Candidate for the Treatment of Generalized Epilepsies. Journal of Medicinal Chemistry, 60, 9769-9789.

https://doi.org/10.1021/acs.jmedchem.7b01236 https://pubs.acs.org/doi/10.1021/acs.jmedchem.7b01236

[38] Li, X.Q., et al. (2016) Discovery of a Novel Microsomal Epoxide Hydrolase-Catalyzed Hydration of a Spiro Oxetane. Drug Metabolism \& Disposition, 44, 13411348. http://dmd.aspetjournals.org/content/dmd/44/8/1341.full.pdf https://doi.org/10.1124/dmd.116.071142

[39] Morisseau, C. and Hammock, B.D. (2005) Epoxide Hydrolases: Mechanisms, Inhibitor Designs, and Biological Roles. Annual Review of Pharmacology and Toxicology, 45, 311-333. https://doi.org/10.1146/annurev.pharmtox.45.120403.095920 https://www.annualreviews.org/doi/abs/10.1146/annurev.pharmtox.45.120403.0959 20?rfr_dat=cr_pub\%3Dpubmed\&url_ver=Z39.88-2003\&rfr_id=ori\%3Arid\%3Acros sref.org\&journalCode $=$ pharmtox

[40] Vaclavikova, R., Hughes, D.J. and Soucek, P. (2015) Microsomal Epoxide Hydrolase 1 (EPHX1): Gene, Structure, Function, and Role in Human Disease. Gene, 571, 1-8. https://www.sciencedirect.com/science/article/abs/pii/S0378111915009129?via\%3Di hub https://doi.org/10.1016/j.gene.2015.07.071

[41] Toselli, F., et al. (2017) Oxetane Substrates of Human Microsomal Epoxide Hydrolase. Drug Metabolism \& Disposition, 45, 966-973. http://dmd.aspetjournals.org/content/dmd/45/8/966.full.pdf https://doi.org/10.1124/dmd.117.076489

[42] Hutzler, J.M., Obach, R.S., Dalvie, D. and Zientek, M.A. (2013) Strategies for a Comprehensive Understanding of Metabolism by Aldehyde Oxidase. Expert Opinion on Drug Metabolism \& Toxicology, 9, 153-168.

https://www.tandfonline.com/doi/abs/10.1517/17425255.2013.738668?journalCode =iemt20 https://doi.org/10.1517/17425255.2013.738668

[43] Foti, R.S. and Dalvie, D.K. (2016) Cytochrome P450 and Non-Cytochrome P450 Oxidative Metabolism: Contributions to the Pharmacokinetics, Safety, and Efficacy of Xenobiotics. Drug Metabolism \& Disposition, 44, 1229-1245. http://dmd.aspetjournals.org/content/dmd/44/8/1229.full.pdf https://doi.org/10.1124/dmd.116.071753

[44] Argikar, U.A., Potter, P.M., Hutzler, J.M. and Marathe, P.H. (2016) Challenges and Opportunities with Non-CYP Enzymes Aldehyde Oxidase, Carboxylesterase, and UDP-Glucuronosyltransferase: Focus on Reaction Phenotyping and Prediction of Human Clearance. The AAPS Journal, 18, 1391-1405.

https://link.springer.com/article/10.1208\%2Fs12248-016-9962-6 https://doi.org/10.1208/s12248-016-9962-6

[45] Jensen, K.G., et al. (2017) Lack of Exposure in a First-in-Man Study Due to Aldehyde Oxidase Metabolism: Investigated by Use of 14C-microdose, Humanized Mice, Monkey Pharmacokinetics, and in Vitro Methods. Drug Metabolism \& Disposition, 45, 68-75. http://dmd.aspetjournals.org/content/dmd/45/1/68.full.pdf https://doi.org/10.1124/dmd.116.072793 